\title{
SIMILITUDES Y DIFERENCIAS ENTRE LA “IRONÍA ROMÁNTICA" Y LA FIGURA DEL ESPÍRITU DENOMINADA “ALMA BELLA” EN LA FILOSOFÍA DE HEGEL
}

\author{
Carlos Víctor Alfaro \\ Universidad Nacional de Rosario, Argentina \\ bttp://dx.doi.org/10.15304/ag.38.1.4494
}

\section{Resumen}

Observamos una estrecha relación entre el "alma bella" y la ironía romántica. Pero dicho vínculo no puede confundirse con la identificación entre una y otra. El "alma bella" se desdobla en dos lados: la conciencia juzgante y la conciencia actuante. La primera proclama que intuye la ley moral y juzga las acciones de la conciencia que actúa según la normatividad intuida. La segunda sostiene que actúa según su interpretación particular del deber. Las similitudes entre ambas ocultan diferencias que serán presentadas en el artículo.

Palabras clave: Hegel, Schlegel, alma bella, ironía, deber, acción, juicio.

\begin{abstract}
We observe a narrow relation between the "beautiful soul" and the Romantic irony. But this link cannot be mistaken with the identification between both. The "beautiful soul" split in two sides: the judging consciousness and the acting consciousness. The first one states that she intuits the moral law and judges the actions of the acting consciousness according to the intuited normativity. The second one states that she acts according to her particular lecture of duty. Similarities between both hide differences that will be shown in the paper. Keywords: Hegel, Schlegel, beautiful soul, irony, duty, action, judgment.
\end{abstract}

Recibido: 18/12/2017. Aceptado: 29/05/2018. 
Numerosos intérpretes asumen que el pensador suabo incluía implícitamente a los ironistas dentro del elenco de pensadores cuya filosofía puede clasificarse como el pensamiento de un "alma bella". Pinkard sostiene que el "alma bella", incapaz de actuar en el mundo por miedo a quebrar su armonía interna, evoluciona en la constitución de dos figuras: la conciencia que juzga, y el ironista -que es la conciencia que actúa- ${ }^{1}$. Otros comentaristas se refieren específicamente a la obra de Friedrich Schlegel ${ }^{2}$. Harris sostiene que Lucinde nos entrega un ejemplo del "solitario servicio divino" que Hegel le atribuye al "alma bella" . El comentarista considera que el deseo insatisfecho de esta figura del Espíritu es representado por los protagonistas de la mencionada novela de Schlegel: Julius y Lucinde ${ }^{4}$. Finalmente, Harris

${ }^{1}$ Pinkard, Terry, capítulo 7: "What is a 'shape of the spirit'?”. En AAVV, Hegel's Phenomenology of Spirit. A critical guide. Cambridge University Press, New York, 2008, pp. 112-129. Página 126: "Moreover, each of these fantasies understands itself not as a version of a single 'shape of consciousness' but as rival and opposed ways of life; each sees the other as what Kant called 'radical evil', the perpetual temptation to substitute one's own self-love for the messiness of trying to sort out the moral law in the real world, with the judgmental moralist seeing the ironist as an attempt to flee responsibility, and the ironist seeing the judgmental moralist as somebody trying to impose his own contingent set of values on others under the pretext of claiming universal validity for them.

In Hegel's own dialectic, he imagines one of these actors -the ironist, the 'free spirit'coming to see that in fact all of his actions really do constitute who he is and that rather than preserving his moral conscience intact throughout his refusal to identify himself with any particular plan or action, he has in fact come to be more like an instance of 'radical evil' itself. In Hegel's narrative, he confesses this to the judgmental moralist since he, in Hegel's words, intuits (has an 'Anschauung' of) himself in the other, and both finally end up confessing their one-sidedness to each other in acts of forgiveness and reconciliation, which constitute, as Hegel puts it, 'a reciprocal recognition which is absolute spirit'."

${ }^{2}$ Vid. Schlegel, Friedrich, Lucinde. Stuttgart, Christ. Hausmannschen Antiquariats-Buchhandlung, 1835. La novela narra la historia de amor entre Julius y Lucinde. Las reflexiones de los dos amantes acerca de su relación afectiva trascienden los límites de su singularidad, para adentrarse en el terreno de la especulación respecto a la condición humana en general y del amor en particular.

${ }^{3}$ Harris, H.S., Hegel's Ladder II: The Odyssey of Spirit. Estados Unidos de América, Hackett Publishing Company, Inc. 1997, p. 481: "A novel like Lucinde, or the Lehrlinge zu Sais of Novalis is the outward expression (the 'intuition') of this lonely 'divine service' as an object of consciousness."

${ }^{4}$ Op. cit., p. 484: "The Beautiful Soul is the Unhappy Self-Consciousness, but it does not feel like that. It feels 'happy' for the very same reason that the Unhappy Consciousness is 'unhappy': because it cannot achieve any abiding 'objectivity'. The Unhappy Consciousness cannot overcome the world; the Beautiful Soul will not let the objectivity of the world count for anything. It lives in its own dream world instead.

Even Julius and Lucinde in Schlegel's literary vision exemplify this extreme. Their life together is an image of 'Pleasure' unshadowed by 'Necessity'; and we know that that is what 
sostiene que los personajes en cuestión ejemplifican la falta de compromiso histórico y social que caracteriza a la bella subjetividad ${ }^{5}$. Speight afirma que el desarrollo de la conciencia que actúa es una alusión a la escena del "desenmascaramiento del alma bella", que acontece en Lucinde 6 . Hirsch considera que la oposición entre la conciencia que juzga y la conciencia que actúa -definida como el "mal" por la primera-, tiene un referente histórico: Friedrich Schlegel y su novela Lucinde $e^{7}$ Behler adhiere a la hipótesis de

they wish for, rather than what they actually experience. Julius claims that they have actually achieved the Garden of Eden pictured in sentimental love stories."

${ }^{5}$ Op. cit., p. 486: "All of the 'beautiful souls' are devoted to 'good works'; but their private domestic activity is not historical action. Historical commitment is what all of the beautiful souls are afraid of (and only Hyperion overcomes the fear). As far as the public world is concerned, they are satisfied with preaching and pious talk. The figure for whom his whole 'world' is just the echo of his talk is easily recognized as the Heinrich von Ofterdingen of Novalis. But the one who actually goes home to his garden -specifically to the Garden of Eden- is Julius with his Lucinde; and in that instance the avoidance of Dasein takes an important symbolic form. In their private Paradise the 'outward action and thereness' of a formal marriage service is deliberately avoided. Their marriage is a 'conscientious' one; they say they are married, and that makes it so."

${ }^{6}$ Speight, Allen, Hegel, literature and the problem of agency. Cambridge, Cambridge University Press, 2004, pp. 109-110: “The contest in this final section of the PhG between an acting and a judging beautiful soul is one that is sketched, as is usually thought, by means of allusions to representative figures from the 'beautiful soul' literature: for the acting soul, the scene of confession and unmasking of the beautiful soul that occurs in the 'Allegory of Impudence' in Schlegel's Lucinde; for the judging soul, Jacobi's Allwill or Woldemar -or perhaps more often the poet Hölderlin is thought to be the model."

Vid. Schlegel, Friedrich, Lucinde, p. 25. Schlegel denuncia la hipocresía del alma bella en "Allegorie der Frechheit". El alma bella afirma su modestia frente a los demás, pues se niega a intervenir en la sociedad. Sostiene que la intervención social implicaría la manipulación del otro. Es decir, los demás serían tratados como medios para un fin, y no fines en sí mismos. Pero tras esta máscara de supuesta virtud se oculta un temperamento ególatra, narcisista, que se identifica a sí mismo con la voz de lo divino. La crítica a la inmoralidad del sujeto de la acción refleja la exigencia de una armonía entre la actividad finita y el trasfondo ético infinito del cual la conciencia es supuestamente consciente. Sin embargo, dicha armonía es imposible de alcanzar por una conciencia individual actuante. El alma bella es consciente de la imposibilidad de coordinar una acción singular con su propia intuición del deber universal. Por este motivo, renuncia a la acción y se dedica a juzgar a quienes actúan. Pero las críticas hacia los demás presuponen que esta ha alcanzado la intuición de lo infinito y se ubica en el lugar del saber divino. Según Schlegel, semejante presunción es una clara muestra de vanidad.

${ }^{7}$ Hirsch, Emanuel, “Die Beisetzung der Romantiker in Hegels Phänomenologie”. En Materialen zu Hegels "Phänomenologie des Geistes". Frankfurt am Main, Suhrkamp Verlag, 1973, pp. 245-75. Página: 259. “Die Unfähigkeit der schönen Seele, sich an das Wirkliche hinzugeben, und die Unfähigkeit der urteilenden Gewissens, mit dem Bösen als einer 
lectura de Hirsch, y afirma que la superación de la hipocresía por medio de la confesión del mal -ínsita en la Fenomenología del Espíritu-, es una referencia ineludible a la obra de Friedrich Schlegel ${ }^{8}$.

Hegel alude al pensamiento de Schlegel tanto en Rasgos fundamentales de la Filosofía del Derecho, o compendio de derecho natural y ciencia del Estado, como en las Lecciones sobre la estética. En ambos casos se observa una estrecha relación entre la mencionada figura del Espíritu y la ironía romántica ${ }^{9}$. Pero dicho vínculo no puede confundirse con la identificación entre una y otra. El "alma bella" se desdobla en dos lados: la conciencia juzgante y la conciencia actuante. La primera proclama que intuye la ley moral y juzga las acciones de la conciencia que actúa según la normatividad

Geistgestalt sich in Mitteilung zu setzen, erscheinen als dasselbe, das sich nur in verschiedenen Beziehungen geltend macht...

So ist mir denn auch keinem Zweifel unterlegen, daß bei dem sich selbst in seiner Heuchelei entlarvenden Bösen von Hegel an Schlegels ,Lucinde“ gedacht ist.”

${ }^{8}$ Behler, Ernst, "Hegel und Friedrich Schlegel". En Studien zur Romantik und zur idealistischen Philosophie. Paderborn, Ferdinand Schöningh, 1988, pp. 9-45. Página 10: "Bereits in der Phänomenologie begegnet uns Schlegel an einem wichtigen Umschlagspunkt des Hegelschen Denkens, nämlich im letzten Abschnitt des Kapitels über die Moralität, der sich mit dem Gewissen beschäftigt. Die große Bedeutung dieses Kapitels liegt darin, daß es die unmittelbare Vorstufe zum absoluten Geist, also zum höchsten Punkt der Hegelschen Philosophie bildet. In einer berühmten Untersuchung hat Emanuel Hirsch herausgearbeitet, daß dieses Kapitel über die Moralität neben der gedaklichen Evolution auch eine historische, zeitgeschichtliche Entwicklung der Philosophie zum Ausdruck bringen will. So habe Hegel in den beiden ersten Abschnitten über die ,moralische Weltanschauung' und ihre ,Verstellung‘ Kant im Auge gehabt. Der folgende Abschnitt über das Gewissen, mit den Erscheinungen der ,moralischen Genialität', der ,absoluten Gewißheit seiner Selbst' als ,reine Anschauung des Ich = Ich', der ,schönen Seele‘, der ,Heuchelei', des ,Bösen“ und des ,harten Herzens', bringe ,die Eigenart der romantischen Bewegung' zum Ausdruck, indem die Position der moralischen Genialität auf Jacobi, die der reinen Anschauung des Ich = Ich auf Fichte, die Problematik der schönen Seele auf Novalis, die Überwindung der Heuchelei durch das deklarierte Böse auf Friedrich Schlegel und schließlich die Manifestation des harten Herzens auf Hölderlin zu beziehen sei. In der Gestalt der, Verzeihung a aber habe Hegel seine eigene Philosophie gezeichnet, ,in der die Zerrisenheit des romantischen Bewußtseins in Böses und schöne Seele gelöst und aufgehoben wird“."

${ }^{9}$ Vid. Hegel, Georg Wilhelm Friedrich, Vorlesungen über die Geschichte der Philosophie. Tercer tomo. Decimoquinto tomo de Georg Wilhelm Friedrich Hegel's Werke: Vollständige Ausgabe durch einen Verein von Freuden des Verewigten. Berlín, editado por Duncker y Humblot, 1836, p. 642. Vid. Hegel, Georg, Wilhelm Friedrich, "Solgers nachgelassene Schriften und Briefwechsel”. Segundo artículo. En G.W.F. Hegel: Berliner Schriften 18181831, Werke 11. Frankfurt am Main, Suhrkamp Verlag, 1970., pp. 205-74. Cf. Paha, Bernhard, Die schöne Seele Hegels und die Literatur der Frühromantik: Studienarbeit. Alemania, GRIN Verlag, 1992; pp. 19-22, 27-29. Cf. Rorty, Richard, Contingency, irony and solidarity. Estados Unidos de América, Cambridge University Press, 1989, pp. 73-121. 
intuida. La segunda sostiene que actúa según su interpretación particular del deber. La conciencia que actúa es el "mal" que se opone a la conciencia que juzga, porque no actúa en armonía con el deber universal. Cuando la conciencia actuante reconoce que su lectura de la ley moral es una determinación particular, asume que ha actuado con "maldad". La conciencia irónica, en cambio, no reconoce que exista una esencia universal que la trascienda. Por este motivo, el ironista no reconoce que actúe con "maldad". Pues este último no asume que haya infringido ninguna ley.

\section{La concepción de "alma bella” en la filosofía de Hegel}

La figura del Espíritu conocida como "alma bella" se desdobla en la conciencia del deber y la autoconciencia. La primera instancia se caracteriza porque es la intuición de la universalidad del deber. Este no es intuido como una esencia de la realidad ética exterior, sino como una determinación propia. Es decir, la conciencia intuye su propio contenido como el deber universal. La autoconciencia es el momento de reconocimiento de la intuición de sí como intuición de la universalidad del deber. Luego, la autoconciencia del alma bella reconoce que ella se impone su propia ley moral: ella se condiciona a sí misma. El alma bella asume que no es condicionada por factor externo alguno; o, lo que es lo mismo, que es incondicionada. Lo incondicionado es lo absoluto o divino. Por consiguiente, la autoconciencia del alma bella asume que ella es lo divino que se intuye a sí mismo ${ }^{10}$.

El vínculo entre ambas instancias se constituye como una igualdad, pues la autoconciencia posee el mismo contenido que la conciencia del deber. Por este motivo, Hegel declara que "la autoconciencia ha retornado ahora a su refugio más íntimo, ante el que desaparece toda exterioridad como tal, a la intuición del yo $=$ yo, donde este yo es toda esencialidad y toda existencia" ${ }^{11}$. Sin embargo, la autoconciencia y la conciencia del deber no comparten la misma determinación formal. En primer lugar, la autoconciencia es una determinación individual. Es decir, esta es una singularidad afectada por factores particulares. En segundo lugar, la conciencia del deber es una determinación universal: ella es la intuición de la esencia universal contenida en ella misma. La relación establecida entre la autoconciencia

${ }^{10}$ Vid. Hegel, Georg Wilhelm Friedrich, Fenomenología del Espíritu. Traducción de Wenceslao Roces con la colaboración de Ricardo Guerra. México DF, Fondo de Cultura Económica, 1966, pp. 464-5.

${ }^{11}$ Op. cit., p. 383. 
y la conciencia del deber es una identidad abstracta, ya que no contempla las determinaciones del individuo y el universal intuido. Semejante relación sólo es posible si la autoconciencia permanece abstraída de las particularidades del mundo exterior, pues el yo individual se objetiva en la acción. La subjetividad del yo individual se manifiesta eventualmente en un resultado objetivo, mediante la acción concreta en la exterioridad. La objetividad conquistada es una existencia finita, determinada en un espacio y tiempo concretos. Una autoconciencia que asume su finitud no puede identificarse con la conciencia del deber, pues la universalidad abstracta de la ley moral no se adecúa a las particularidades de una individualidad concreta ${ }^{12}$.

El alma bella "vive en la angustia de manchar la gloria de su interior con la acción y la existencia"13. Ella experimenta toda transformación como la destrucción de sí misma. Por ello permanece en la abstracción y rehúsa la concreción de su pensamiento:

El objeto hueco que se produce lo llena, pues, ahora, con la conciencia de la vaciedad; su obrar es el anhelar que no hace otra cosa que perderse en su hacerse objeto carente de esencia y que, recayendo en sí mismo más allá de esta pérdida, se encuentra solamente como perdido; - en esta pureza transparente de sus momentos, un alma bella (desgraciada), como se la suele llamar, arde consumiéndose en sí misma y se evapora como una nube informe que se disuelve en el aire. ${ }^{14}$

Hegel compara el alma bella con la conciencia desgraciada, pues la mencionada figura de la conciencia también se desdobla en dos instancias: una conciencia que percibe y una conciencia percibida. La primera es el "ser para sí" individual y la segunda es el "ser en sí” universal. La conciencia que percibe no asume que lo percibido es ella misma. Por este motivo, la individualidad que es para sí experimenta al "ser en sí" universal como una esencia ajena. La esencia universal percibida es aprehendida como lo divino, lo absoluto; como Dios. La conciencia percipiente, en cambio, se concibe como el individuo que no puede acceder a este reino de lo divino. Ella considera que la imposibilidad de acceso implica su falta y causa de su vergüenza. No es capaz de comprender que el 'en sí' al cual adora como lo divino es su propia esencia ${ }^{15}$.

Del mismo modo, el alma bella se percibe como la autoconciencia que ha sido puesta por el deber ser universal. Cuando enuncia que es consciente de

\footnotetext{
12 Vid. op. cit., p. 384.

${ }^{13}$ Op. cit., p. 384.

${ }^{14} \mathrm{Op}$. cit., p. 384. [Los términos entre paréntesis son nuestros].

${ }^{15}$ Vid. op. cit., pp. 128-39.
} 
sí, sostiene que es consciente de ser determinada por la ley que ha concebido como universal. El individuo debe actuar en consonancia con su ley interior. Si cometiera un acto que no se ajustara a lo establecido por esta última, se intuiría alienada del universal. Su negativa al reconocimiento de los móviles patológicos que impulsan sus decisiones implica el rechazo a su propia determinación individual concreta. Su individualidad es una abstracción de los atributos particulares que la constituyen como individuo. La expresión más clara de esta situación es la censura al momento de actuar: el alma bella se limita a juzgar a las conciencias que actúan. Su abstención con respecto a todo aquello que rebase el plano de lo meramente discursivo también está fundada en la negación de su individualidad concreta. Si el alma bella actuara, su acción estaría limitada por las condiciones espaciotemporales, históricas, culturales en las que todo acto se encuentra condicionado. Más aún, el impulso interior que la conduciría a la acción no sería el respeto a la objetividad del deber, sino la subjetividad expresada en el sentimiento personal de satisfacción por la exteriorización de su propia interioridad.

El alma bella se desdobla en dos lados: una conciencia que juzga y una conciencia que actúa. El objeto de esta última es una determinación particular del mundo exterior. Luego, el deber no es el objeto de la conciencia actuante, pues este es un universal. La conciencia que actúa sostiene que la universalidad abstracta del deber no se adecúa a las particularidades que enfrenta en su actividad, y afirma que aplica la ley moral con arreglo a su praxis. La conciencia juzgante sostiene que el comportamiento de la conciencia actuante es una inmoralidad, ya que considera que la reducción de la universalidad del deber a una mera interpretación personal es la negación de la ley moral. Pues la ley es un parámetro universal que no puede adecuarse a cada instancia particular que se presente. La conciencia actuante se defiende de tal acusación y sostiene que ella actúa de acuerdo con su intuición del deber. Sin embargo, ella observa que ninguna otra subjetividad actúa en concordancia con su interpretación particular de la ley moral. Luego, la conciencia que actúa reconoce que la normatividad que se ha impuesto no es universal, sino una interpretación particular que se adecúa a sus intereses egoístas. Por este motivo, la conciencia actuante confiesa que ha actuado con "maldad" y suplica perdón a la conciencia que juzga por su inmoralidad.

La conciencia que actúa no concibe su confesión como una humillación, pues considera que la conciencia que juzga es culpable de la misma inmoralidad en la que ella ha incurrido. En primer lugar, ella ha observado que la conciencia que juzga intuye el deber como una determinación de su propio 
contenido. O sea, el deber intuido es su propia ley interior. La conciencia que juzga rechaza esta acusación y considera que su juicio se basa en la intuición del deber tal como es "en sí”. Pero las posturas de las demás conciencias, que sostienen interpretaciones particulares divergentes del deber, demuestran que su intuición del deber universal es tan sólo otra interpretación particular de la ley moral.

En segundo lugar, la conciencia juzgante considera que la actividad de la conciencia actuante presupone la desigualdad entre la universalidad del deber y la autoconciencia. Ella considera que es preferible la inacción antes que la realización de una actividad que implique la oposición al deber universal. Pero la enunciación de juicios también es una acción. La conciencia que juzga sostiene que la denuncia de acciones que no han sido motivadas exclusivamente por el respeto al deber es una obligación moral. Pero las críticas realizadas por la conciencia que juzga se fundan en su interpretación particular del deber. Por este motivo, sólo la propia conciencia que juzga considera que su crítica a la actividad de los demás es una acción en concordancia con la ley moral. El discurso crítico de la conciencia que juzga se funda en la igualdad del contenido de la interpretación particular del deber y el contenido de la autoconciencia. Es decir, el fundamento de su actividad es la igualdad entre una determinación particular y su propia autoconciencia. Luego, la conciencia que juzga comete la misma inmoralidad que la conciencia que actúa. A saber, ella actúa determinada por particularidades, y no en consonancia con el deber universal. El fundamento de sus juicios es la desigualdad entre el lado universal y el lado individual. Su crítica a la conciencia que actúa se funda en un interés egoísta: la vanagloria del alma bella, que se considera virtuosa frente a la conciencia que actúa.

El alma bella niega que su condición de conciencia que juzga sea motivada por un interés personal. Su rechazo a la intervención de determinaciones particulares en la realización de una actividad resulta en la abstracción con respecto al mundo exterior. Ella es un individuo que repele la comunidad con el otro, para conservarse como singularidad. Se rebela contra el Espíritu. Su rebelión es el intento de sostener la igualdad consigo misma como la realidad desde la cual juzga a los demás. Pero el Espíritu tiene la potestad de la realidad efectiva. Los individuos actúan en el marco del Espíritu universal que los rebasa y comprende. El Espíritu abarca y trasciende a los humanos y los vínculos que sostienen entre sí: los miembros de una sociedad comparten el universal como aquello que tienen en común. Un hombre puede exponer su particular perspectiva del mundo y de las relaciones humanas para actuar con arreglo a sus preceptos, pero no puede imponer 
los mismos a los demás, y menos aún esperar que los acontecimientos se desarrollen según lo que haya proyectado.

\section{La concepción de ironía romántica en la filosofía de Hegel}

Hegel adjudica la invención de la ironía a Friedrich Schlegel. El filósofo alemán afirma que: "El señor Friedrich von Schlegel inventó esta ironía, que tanto ha dado que hablar" ${ }^{16}$. Con esta aseveración, Hegel también sostiene implícitamente que la ironía no puede ser considerada una figura del Espíritu, ya que estas últimas no son la "invención" de un pensador solitario, sino una determinación de la sustancia espiritual ${ }^{17}$. Según el filósofo alemán, Schlegel concibió la ironía como un método de crítica del arte, basándose en la filosofía de Fichte:

Ahora bien, en lo que atañe a la más estrecha conexión de las propuestas de Fichte con una de las tendencias de la ironía, basta con destacar a este respecto el siguiente punto: como principio absoluto de todo saber, de toda razón y conocimiento, Fichte establece el yo, y ciertamente el yo que permanece completamente abstracto y formal. ${ }^{18}$

Hegel no considera que el sistema fichteano deba ser catalogado como una muestra de la ironía romántica. Fichte no concibe al Yo absoluto como una conciencia individual. Pero Schlegel sostiene que la subjetividad singular es la yoidad absoluta ${ }^{19}$. Para el poeta alemán, el yo psicofísico es el fundamento último de la realidad ${ }^{20}$. Hegel afirma al respecto:

Este yo es entonces por ello, en segundo lugar, de todo punto simple en sí, y, por una parte, en él se niega toda particularidad, [determinación], todo contenido - pues todo

${ }^{16}$ Hegel, Georg Wilhelm Friedrich, Lecciones sobre la estética, Traducción de Alfredo Brotóns Muñoz. Madrid, Ediciones Akal, S.A., 1989, p. 51.

${ }^{17}$ Una figura del Espíritu es una manifestación cultural o "visión del mundo" compartida por una cultura en un momento histórico determinado. Los miembros de una cultura participan en la constitución de la figura del Espíritu, pero no son sus inventores. Ellos incluso pueden no ser conscientes de su participación en una figura del Espíritu particular, pero reproducen sus determinaciones. La figura del Espíritu abarca a todas las individualidades de una corriente cultural y las trasciende. Por ejemplo, Novalis y Jacobi son exponentes de la figura del Espíritu conocida como "alma bella". Ninguno de ellos la ha inventado, pero su obra literaria es un fiel reflejo de esta forma de ver el mundo.

${ }^{18}$ Op. cit., p. 50.

${ }^{19}$ Vid. Hegel, Georg Wilhelm Friedrich, Rasgos fundamentales de la Filosofía del Derecho o compendio de derecho natural y ciencia del Estado. Traducción de Eduardo Vázquez. Madrid, Editorial Biblioteca Nueva, 2000, \$140, Adición, p. 220.

${ }^{20}$ Vid. Henrich, Dieter, Between Kant and Hegel: Lectures on German Idealism. Estados Unidos, Harvard University Press, 2003, pp. 225-30. Vid. Dupuy, Rosario Casas, “Apuntes 
se hunde en esta libertad y unidad abstractas-, y, por otra parte, todo contenido que deba ser válido para el yo sólo es como puesto y reconocido por el yo. Lo que es, es sólo por el yo, y lo que es por mí, igualmente también puedo aniquilarlo. Ahora bien, si nos quedamos en estas formas enteramente vacías que tienen su origen en la absolutidad del yo abstracto, nada es considerado en y para sí ni en sí mismo valioso, sino sólo en cuando producido por la subjetividad del yo. Pero entonces también el yo puede permanecer dueño y señor de todo, y ni en la esfera de la eticidad, ni de la legalidad, de lo humano ni de lo divino, ni de lo profano ni de lo sagrado, hay nada que no haya de poner primero el yo y que, por tanto, no pueda igualmente ser destruido por el yo. Por eso todo lo-que-es-en-y-para-sí es sólo una apariencia, no verdadero y efectivamente real por sí mismo y a través de sí mismo, sino un mero aparecer a través del yo, a la libre disposición de cuyo poder y arbitrio permanece. Aceptar o superar dependen mutuamente del antojo del yo, en sí en cuanto yo ya absoluto. ${ }^{21}$

Toda la realidad puede ser reducida al pensamiento. Es decir, toda particularidad existente tiene su fundamento en la conciencia que la percibe y concibe. Todo contenido particular es una determinación de la forma del pensamiento. De esta manera, la realidad sólo es tal, en tanto es pensada. Por otro lado, la existencia de cualquier pensamiento particular depende de su relación con la conciencia que lo piensa. Ningún pensamiento es en-sí-ypara-sí, sino para-otro: es un ser-para-la-conciencia que lo piensa. Si el pensamiento es para la conciencia, entonces es su objeto. Luego, la subjetividad del yo es el fundamento de todo contenido particular. Lo único valioso en y por sí mismo es el yo. No existe ley, divina o humana, que esté por encima de la subjetividad ${ }^{22}$. La conciencia individual hace experiencia de su libertad cuando se abstrae de toda determinación exterior. Todo aquello que la subjetividad percibiera como existente por sí mismo es sólo una apariencia, ya que todo es por medio del propio yo subjetivo ${ }^{23}$.

sobre la crítica hegeliana de la ironía”. En Ideas y Valores, № 110, Agosto 1999, Bogotá, Colombia, pp. 21-31. Vid. Taylor, Charles, Hegel. New York, Cambridge University Press, 1975, pp. 34-47. Vid. Taylor, Charles, Hegel and modern society. Cambridge, Cambridge University Press, 2003, p. 13. Vid. Benjamin, Walter, El concepto de crítica de arte en el romanticismo alemán. Barcelona, Ediciones Península S.A., 1998, pp. 41-9. Vid. Kierkegaard, Soren, Sobre el concepto de ironía. Volumen 1 de Soren Kierkegaard: Escritos. Madrid, Editorial Trotta, 2000, pp. 293-8. Vid. Pöggeler, Otto, Hegels Kritik der Romantik. Bonn, H. Bouvier u. Co. Verlag, 1956, pp. 66-9.

${ }^{21}$ Hegel, Georg Wilhelm Friedrich, Lecciones sobre la estética, p. 50. Los términos entre corchetes son míos.

${ }^{22}$ Vid. Knowles, Dudley, Hegel and the Philosophy of Right. Londres, Routledge, 2002, p. 219. La conciencia irónica sigue las reglas morales convencionales, pero les niega una realidad objetiva.

${ }^{23}$ Vid. Dupuy, Rosario Casas, “Apuntes sobre la crítica hegeliana de la ironía”, pp. 2131. Vid. Lukács, Gyorgy, Ein geschichtsphilosophischer Versuch über die Formen der großen Epik. Berlín, editado por Paul Cassirer, 1920. 
Hegel también analiza la postura del ironista como sujeto de la acción ${ }^{24}$. Pues la conciencia irónica no se limita a la negación de lo pensado, sino que también actúa. La existencia de todo ser humano consiste en la exteriorización de su vida interior. Es decir, la realización de su pensamiento. El filósofo alemán observa que los postulados sobre los cuales se sustenta la perspectiva teórica del ironista inciden en el desarrollo de su praxis. El pensador alemán se refiere específicamente a la obra del artista, pues la concepción de ironía formulada por Schlegel se centraba en la actividad artística. Al respecto, Hegel sostiene:

Respecto a lo bello y al arte, esto tiene $e l$ sentido de vivir como artista y configurar artísticamente la vida de uno. Pero, según este principio, yo vivo como artista cuando mi acción y exteriorización en general, en tanto que afectan a un contenido cualquiera, resultan para mí sólo una apariencia y adoptan una figura que está enteramente en mi poder. En tal caso no me tomo verdaderamente en serio ni este contenido ni su exteriorización y realización efectiva. ${ }^{25}$

Como el yo psicofísico es el fundamento último de la realidad, el artista no debe preocuparse por la temática central en torno a la cual gira la obra de arte. El trasfondo intelectual carece de importancia. Desde la perspectiva del ironista, no existe asunto que sea más relevante que otro. El contenido eidético no es, en sí mismo, esencial. Lo único esencial es el enfoque del artista acerca del tópico elegido, ya que la conciencia de este es el fundamento absoluto de toda creación artística. Por otro lado, tampoco importa el resultado final alcanzado. Es decir, la obra de arte tampoco es esencial. Los juicios efectuados sobre la misma carecen de importancia. Sólo la visión que tiene su hacedor es relevante. Tanto el trasfondo intelectual como la obra de arte son la apariencia, el reflejo exteriorizado de la interioridad esencial del artista. Las críticas que puedan formularse a su producción artística no atienden lo fundamental en estas circunstancias: la conciencia artística que les ha insuflado vida. El único juez idóneo para este asunto es su propio creador, ya que es el único que realmente conoce el fundamento esencial que ha determinado la realización material de su enfoque.

Hegel afirma que la existencia humana se sustenta en la exteriorización de la interioridad individual. Pero sostiene que los parámetros bajo los cuales lo realizado debe ser analizado no pueden ser reducidos a la conciencia de quien lo realiza. Si este fuera el caso, no existiría nada en común entre los miembros de la comunidad. Pues cada uno tendría su perspectiva sobre lo

\footnotetext{
${ }^{24}$ Vid. Hegel, Georg Wilhelm Friedrich, Lecciones sobre la estética, p. 50.

${ }^{25}$ Op. cit., p. 50.
} 
que resulta relevante y lo que resulta irrelevante. Más aún, cada individuo devendría único juez acerca de lo excelso o deplorable de sus acciones. El significado de toda acción ejecutada sólo podría ser aclarado por quien lo realizara. Las acusaciones que otros pudieran hacerle no tendrían validez alguna, ya que el fundamento de todo acto yace oculto en la interioridad de su agente. Esta postura, que el pensador alemán critica vehementemente, es la perspectiva de la genialidad divina ${ }^{26}$. El genio irónico es una figura de la que hace gala Schlegel: el artista incomprendido por un público demasiado inculto e ignorante como para apreciarlo. Tras la frustración que siente el ironista por la supuesta incomprensión de la que es víctima, se oculta el desprecio hacia los restantes miembros de la sociedad. El genio irónico ve en el otro a un hombre incapaz de asumir que las normas y juicios de valor impuestos por la sociedad a la que pertenece no son valiosos por sí mismos: un individuo esclavizado por su propia necedad ${ }^{27}$.

\section{Similitudes y diferencias entre el "alma bella” y la ironía}

Hegel traza un nexo explícito entre la ironía y la postura que había denominado en la Fenomenología del Espíritu como el "mal" en ciertos pasajes de la Filosofía del Derecho. En uno de ellos sostiene:

No es la cosa lo excelente, sino que el excelente soy yo, y soy el amo sobre la ley y la cosa, el cual, de ese modo, como su antojo, sólo juega, y en esta conciencia irónica, en la que dejo hundirse lo supremo, sólo gozo de mí mismo.

Esta figura no sólo es la vanidad de todo contenido ético del derecho, el deber y las leyes -el mal, y precisamente el mal universal totalmente en sí (in sich)-, sino que ella añade también la forma, la vanidad subjetiva, de saberse a sí misma como esta vanidad de todo contenido y en este saber saberse como lo absoluto.

Hasta qué punto este absoluto engreimiento no permanece en una aislada latría de sí mismo, sino que acaso también puede formar una comunidad cuyo nexo y substancia es acaso también la seguridad recíproca de escrupulosidad, las buenas intenciones, el regocijo de la mutua pureza, pero especialmente, el deleitarse en el señorío de este saberse y expresarse y en el señorío de este cuidar y fomentar, y hasta qué punto lo que ha sido llamado bella alma, la más noble subjetividad, se extingue en la vanidad de toda objetividad y, de ese modo, en la irrealidad de sí misma, y además otras configuraciones, son peripecias semejantes a los grados considerados

${ }^{26}$ Cf. Norman, Judith, "Squaring the Romantic Circle: Hegel's Critique of Schlegel's Theories of Art". En AAVV, Hegel and Aesthetics. Albany, State University of New York, 2000, pp. 131-44.

${ }^{27}$ Vid. Hegel, Georg Wilhelm Friedrich, Lecciones sobre la estética, pp. 50-3. 
y ya tratados por mí en la Fenomenología del espíritu. Allí puede ser confrontado el capítulo completo Das Gewissen, especialmente también respecto al tránsito a un grado superior en general, allá por lo demás determinado de otro modo. ${ }^{28}$

La conciencia irónica experimenta su poder, ya que niega la excelencia de todo lo pensado y se concibe a sí misma como el fundamento último del pensamiento. El ironista es capaz de restar validez a cualquier noción que se le presente, pues toda concepción es reducida a la relación con la conciencia que la piensa. Su goce consiste en la negación de todas las determinaciones de su objeto: se percibe a sí misma como la negatividad ilimitada, absoluta, de todo lo existente ${ }^{29}$. Luego, la conciencia irónica se da a sí misma una ley interior acorde a sus inclinaciones sensibles como determinación individual. Es decir, adapta la concepción del deber a sus exigencias coyunturales. La conducta del ironista es similar al comportamiento de la conciencia actuante que enfrenta a la conciencia enjuiciadora. Pues tanto la conciencia irónica como la conciencia actuante sostienen que los actos son realizados en concordancia con su propia representación del deber universal. Por este motivo, Hegel sostiene que la conciencia irónica tiene el mal "en sí" (in sich). Es decir, el ironista presenta la desigualdad entre el deber universal y su "sí mismo" en el seno de su conciencia. La "maldad" inherente a la conciencia irónica es la ausencia de concordancia entre el universal y la determinación individual, tal como se presentaba en el caso de la conciencia que actúa.

Sin embargo, el pensador alemán añade una diferencia esencial entre la conciencia irónica y la conciencia que actúa. Hegel sostiene que la primera es consciente de su postura: el ironista sabe que concibe su propia individualidad consciente como lo absoluto. Es decir, la conciencia irónica niega la existencia de una esencia universal. Al hacerlo, asume que ella es la negatividad radical y absoluta. La conciencia actuante considera que actúa acorde al deber universal; y, ante la negativa de la conciencia enjuiciadora, sostiene que ella tiene una interpretación divergente de la ley. Pero la divergencia y contradicción entre las distintas posturas la llevan a preguntarse

${ }^{28}$ Hegel, Georg Wilhelm Friedrich, Rasgos fundamentales de la Filosofía del Derecho o compendio de derecho natural y ciencia del Estado, p. 218.

${ }^{29}$ Vid. Kierkegaard, Soren, Sobre el concepto de ironía, p. 95. La ironía es la negatividad absoluta e infinita, que llama al silencio. Es decir, nos remite a lo inefable. Vid. Hackenesch, Christa, Die Logik der Andersheit. Frankfurt am Main, Athenäum Verlag GmbH, 1987, pp. 131, 192, 238. Lo individual no tiene sentido alguno para Hegel, ya que es indeterminado. Lo inefable no es místico, sino lo no-verdadero (das Unwahres): no es siquiera un error, sino el sinsentido, lo insignificante, lo contingente. 
acerca de la validez de su ley interior. La verdadera buena conciencia asume que actuar en concordancia con su ley interior implica proceder en disonancia con respecto a las demás interpretaciones particulares del deber. La polémica en torno a la representación válida del deber universal significa que la conciencia actuante se niega a actuar en base a una ley interior que no se ajuste correctamente al universal. Luego, la noción de una ley particular interior contradice la concepción del deber universal. Por este motivo, la conciencia que actúa asume que ha procedido con "maldad", ya que sólo es posible conducirse correctamente si se actúa en concordancia con el universal ${ }^{30}$.

La conciencia irónica reconoce la desigualdad entre el universal y su "sí mismo" individual en su propio seno. Sin embargo, el ironista no asume que ha obrado mal, ni pide perdón a la conciencia que juzga, a pesar de observar la incoherencia entre ambos momentos. La conciencia irónica adapta su representación del deber universal a las inclinaciones sensibles propias de su determinación individual; pero es consciente de este proceso. Por este motivo, el ironista asume que la ley interior a la que se somete no es la interpretación del universal. Al contrario, su imagen del "deber" es más bien la lectura que hace de los impulsos, deseos e inclinaciones a los que está sometido coyunturalmente. Luego, su ley interior no es más que el reflejo de sí mismo como lo universal y absoluto. La conciencia irónica sabe que la normatividad y los límites que se ha impuesto no son más que producto de su capricho.

El ironista no busca fundamentos para defender su postura frente a las divergencias entre las interpretaciones acerca del deber universal. Se limita a criticar las posiciones teóricas de los demás. Su crítica a las posturas que se le anteponen consiste en demostrar que el fundamento último de cualquier interpretación respecto al universal es el yo psicofísico que lo concibe como tal. Es decir, reduce todo planteo a la perspectiva particular de una conciencia individual, sometida a las diversas determinaciones espacio-temporales, históricas y culturales. La conciencia irónica cree que todos actúan del mismo modo que ella. Ella sostiene que toda concepción del universal no es más que el reflejo de la determinación individual que lo representa.

\footnotetext{
${ }^{30}$ Vid. Williams, Robert R., "Hegel on Socrates and Irony". En AAVV, Hegel's History of Philosophy: New Interpretations. Albany, State University of New York Press, 2003, pp. $67-$ 86. La ironía y la conciencia de la moralidad tienen un punto de coincidencia: ambas se ponen a sí mismas como negativas. Pero entre una y otra se observa una diferencia relevante: en la moralidad subsiste un interés sustancial en el deber, mientras que la conciencia irónica ha eliminado todo interés sustancial para permanecer ella misma abstracta, vacía e insustancial.
} 
La perspectiva de la conciencia irónica se sostiene en una contradicción que no ha encontrado resolución. Por un lado, la subjetividad se pone a sí misma como lo incondicionado: reduce la universalidad del deber a un serpuesto por ella misma. Se intuye a sí misma como el fundamento absoluto de la realidad. Por otro lado, la subjetividad percibe que es una contingencia, sujeta a determinaciones históricas, sociales y culturales. Es decir, reconoce que es una determinación individual. Como tal, es una singularidad afectada por inclinaciones patológicas. La conciencia irónica respeta la normatividad legal impuesta en una sociedad, aunque considere que la legalidad positiva no es más que una imposición arbitraria. Cualquier reforma de las normas vigentes sería tan improcedente como el antiguo estado de cosas. La sumisión al orden establecido se debe a la coacción que padece el ironista como subjetividad contingente. Hegel piensa incluso que los ironistas pueden formar una comunidad sustentada en la observación de las leyes. Pero la obediencia de la conciencia irónica se produce como resultado de la incapacidad de realizar su yoidad como fundamento último de la Eticidad.

\section{El fracaso de la conciencia irónica y el tránsito al "alma bella"}

Tal como se ha señalado anteriormente, existen ciertas similitudes entre la conciencia irónica y el "alma bella". Tanto el ironista como el individuo que encarna la mencionada figura del Espíritu son capaces de reconocer la desigualdad entre el "deber" universal y su "sí mismo" como determinación individual. Pero también hemos observado diferencias importantes entre ambas instancias. El alma bella intenta trascender esta desigualdad. El ironista, en cambio, no resuelve la incoherencia entre ambos lados. La conciencia irónica suprime el "deber" universal. Este último es reducido a una manifestación de la subjetividad. El yo psicofísico se presenta como el fundamento incondicionado de la realidad exterior. De esta manera, la exterioridad del universal es eliminada. Por otro lado, el ironista reconoce que es una determinación individual fáctica y contingente. Es decir, asume que es una singularidad afectada por las inclinaciones sensibles que padece toda individualidad.

Por consiguiente, la conciencia irónica se desdobla en: a) un yo absoluto, que es el fundamento lógicamente necesario de la realidad exterior; b) una singularidad contingente, que es condicionada por la misma realidad exterior que la conciencia irónica supuestamente determina. La experiencia de poder, consistente en la negación radical de todo lo que es en-y-para-sí 
valioso, se reduce a la abstracción intelectual. El ironista se jacta de una libertad que sólo es aprehensible en sus elucubraciones. En este sentido, la conciencia irónica guarda cierta similitud con la figura de la conciencia denominada "el escepticismo", desarrollada en la Fenomenología del Espí$r i t u^{31}$. El escéptico se caracteriza porque experimenta su libertad como la negación intelectual de todo lo dado. Él intuye que el pensamiento es un ser-para-otro. Este otro -aquél para el cual es el pensamiento-, es la conciencia escéptica que lo intuye. Es decir, la esencia del pensamiento es que sea para la autoconciencia. La existencia del pensamiento no es esencial porque depende de la autoconciencia. La autoconciencia es el único ser eny-para-sí, pues su existencia no depende de otro. Todo lo que se le oponga a la autoconciencia es para ella. Por este motivo, todo lo que se le oponga a la autoconciencia es inesencial. Por otro lado, la autoconciencia es un seren-sí. Luego, ella puede ser concebida como un ser-para-otro, ya que todo ser-en-sí es a la vez para-otro. La autoconciencia, concebida como ser-paraotro, es inesencial. De esta manera, la autoconciencia se desdobla en dos lados: uno de ellos, el ser-para-sí, es lo inmutable, libre y esencial; el otro lado, el ser-para-otro, es lo mudable, contingente e inesencial ${ }^{32}$.

${ }^{31}$ Vid. Hegel, Georg Wilhelm Friedrich, Fenomenología del Espiritu, pp. 124-8.

${ }^{32}$ Vid. Collins, Richard, "The Comic Dissolution of Art: The Last Act of Hegel's 'Aesthetics””. En Theatre Journal, 33:1 (1981:Mar.) pp.60-8. En la tragedia, la sustancia disuelve la subjetividad. En la comedia, la subjetividad disuelve lo inesencial y lo transforma en jocoso. En el escepticismo tragicómico se sostiene la contradicción sin llegar a resolución. Vid. Law, Stephen C., "Hegel and the Spirit of Comedy: Der Geist der stets verneint". En AAVV, Hegel and Aesthetics, pp. 113-30. El comentarista considera que la crítica hegeliana a la sátira se sustenta en el rechazo a la propia idolatría. Según el pensador alemán, el autor de la sátira no busca la reconciliación de los conflictos. El cómico focaliza en la revelación de lo sustancial. Es decir, se concentra en lo objetivo. El autor de la sátira focaliza en su propia subjetividad: se vanagloria de su propia astucia, dejando de lado lo en sí y para sí valioso. La sátira presupone la conciencia escéptica del autor que se afirma a sí mismo como esencial. Para Law, el surgimiento de la sátira significó el fin del arte clásico, tal como lo interpreta Hegel. El advenimiento del escepticismo da paso luego a la conciencia desgraciada. Según el comentarista, Hegel encuentra cierta similitud entre el origen de la sátira y el ocaso del clasicismo ante la irrupción de la ironía romántica. Pero Law aclara que la igualdad es formal. Vid. Pöggeler, Otto, Hegels Kritik der Romantik, pp. 80-93. Lo cómico ya no puede tener el mismo significado que tenía en la forma clásica, pues ésta última presuponía la reconciliación absoluta. El objetivo de la comedia antigua era la disolución de lo que se niega a sí mismo. Es decir, la negación de lo finito e insustancial. De esta manera, prevalecía lo sustancial e infinito. Pero la ironía romántica es la reafirmación de la subjetividad individual presupuesta por la reflexión cristiana del Espíritu, en desmedro de lo sustancial e infinito. Vid. Kierkegaard, Soren, Sobre el concepto de ironía, p. 283. Lo cómico busca la reconciliación entre el particular y el universal. La ironía confirma lo vano, finito, en su vanidad. 
La conciencia irónica padece el mismo desdoblamiento que la autoconciencia escéptica. Por un lado se reivindica como el fundamento esencial de toda la realidad pensada. Por otro lado, se concibe a sí misma como mera apariencia inesencial y contingente, sin fundamento propio alguno. Más específicamente, cuando se afirma como sujeto de la percepción, reduce la realidad exterior a mero objeto del pensamiento. Pero cuando se establece como sujeto de la acción, se intuye a sí misma como una singularidad actuante. Los actos realizados carecen de valor en-y-para-sí, pues son reducidos a un ser-para-la-conciencia que los realiza. Es decir, carecen de valor y significado que trascienda a la subjetividad que los concibe y realiza. La objetividad de la acción es reducida a la subjetividad que los ejecuta. Por este motivo, Hegel sostiene:

Ahora bien, la siguiente forma de esta negatividad de la ironía es, por una parte, la vanidad de todo lo fáctico, ético y en sí pleno de contenido, la nulidad de todo lo objetivo y en y para sí válido. Si el yo queda en esta perspectiva, entonces todo se le aparece como nulo y vano, salvo la propia subjetividad, la cual deviene por ello huera y vacía y ella misma vana. ${ }^{33}$

El ironista, como ser-en-sí, es reducido a ser-para-otro de su propia conciencia. Los móviles que alientan su acción y los actos que realiza son determinaciones singulares, contingentes, inesenciales: la apariencia de su serpara-sí. La conciencia irónica, como ser-para-sí, se sostiene entonces como la esencia absoluta, necesaria e irreductible. Es la negatividad absoluta y radical. Por este motivo, niega radicalmente toda determinación de contenido. Por consiguiente, la conciencia irónica no puede darse un contenido determinado. Esta permanece como la forma simple del Yo.

La conciencia irónica se reduce a su ser-para-sí, vacío de contenido. El ironista se sustrae incluso de sí mismo. Es decir, considera que sus inclinaciones y actos son banales y carentes de relevancia alguna. Hegel continúa: "Pero, por otra parte, el yo tampoco puede, a la inversa, hallarse satisfecho en este goce de sí mismo, sino que debe devenir él mismo menesteroso, de tal modo que ahora sienta la sed de algo firme y sustancial, de intereses determinados y esenciales" ${ }^{34}$. El Yo, abstraído de toda determinación particular, se presenta como el universal indeterminado. No existe acción alguna que pueda manifestarlo. Todo acto realizado está determinado como una determinación particular. Por consiguiente, no logra expresar la universalidad del Yo. La relación existente entre el Yo esencial -el ser-para-sí-, y la

\footnotetext{
${ }^{33}$ Hegel, Georg Wilhelm Friedrich, Lecciones sobre la estética, p. 51.

${ }^{34}$ Hegel, Georg Wilhelm Friedrich, Lecciones sobre la estética, p. 51.
} 
subjetividad como ser-en-sí -que es tan sólo para el Yo esencial-, reproduce aquélla observada en el seno del "alma bella" entre el "deber" universal y la determinación individual.

El ironista ha intentado evadir el conflicto entre el universal y su propio ser-para-sí, negando la universalidad del "deber". La conciencia irónica pretende suprimir la exterioridad del fundamento universal y esencial, para establecerse a sí mismo como la esencia de la realidad exterior. Pero con ello sólo ha logrado establecer su ser-para-sí como el universal. Su para-sí es exterior a él mismo como ser-en-sí y ser-para-otro. Es decir, ha establecido la desigualdad entre los dos lados en el seno de la conciencia. Del mismo modo que la autoconciencia escéptica da paso a la conciencia desgraciada, la conciencia irónica es el tránsito y establecimiento del "alma bella" ${ }^{35}$ :

La insatisfacción por esta quietud e impotencia-que impiden actuar y abordar nada para no renunciar a la armonía interna, y que, pese al ansia de realidad y de absoluto, permanece no obstante efectivamente irreal y vacía, aunque en sí pura- engendra el alma bella y la languidez enfermizas. Pues un alma verdaderamente bella actúa y es efectivamente real. Pero esa ansiedad es sólo el sentimiento de la nulidad del vano sujeto vacío que carece de fuerza para poder escapar a esta vanidad y llenarse de contenido sustancial. ${ }^{36}$

Finalmente, la conciencia irónica replica la relación entre el universal y la determinación individual que presenta la figura del Espíritu denominada "alma bella". El ironista es un tipo humano, cuyo único objetivo es conservar la armonía entre sus dos lados: el ser-para-sí y el ser-en-sí. Sin embargo, la mencionada armonía sólo se logra al precio de la inactividad. Es decir, la coherencia entre los dos lados -universal y singular-, sólo es posible en la más completa pasividad. Luego, el ocaso de la conciencia irónica da paso al "alma bella". El ironista y la conciencia que actúa afirman su ley interior frente al juicio de la conciencia que juzga. Pero la conciencia actuante no pretende perseverar en su "maldad". Al contrario, la conciencia que actúa intenta que la conciencia enjuiciadora reconozca su propia "vileza". Es decir, que asuma su singularidad. Sólo cuando la conciencia que juzga y la conciencia actuante se asuman a sí mismas como determinaciones individuales, será posible una instancia dialógica. En el marco del diálogo entre las dos individualidades se hace visible que el verdadero universal es el Espíritu que los rebasa y contiene. La confesión de la conciencia actuante y la

${ }^{35}$ Vid. Hegel, Georg Wilhelm Friedrich, Fenomenología del Espíritu, pp. 127-8.

Vid. op. cit., p. 384. Hegel define al "alma bella" como una conciencia desgraciada justamente porque se halla escindida entre el para-sí universal y el en-sí individual.

${ }^{36}$ Hegel, Georg Wilhelm Friedrich, Lecciones sobre la estética, p. 51. 
reconciliación con la conciencia que juzga representan el ocaso del "alma bella". O sea, el desarrollo de la conciencia que actúa implica la disolución de la figura del Espíritu antes mencionada.

Hegel presenta al lector el ejemplo de Novalis. El filósofo alemán define el pensamiento de Friedrich von Hardenberg como la perspectiva de un "alma bella". Hegel considera incluso que la propia personalidad de Novalis se ajusta a los criterios establecidos por el "alma bella". Pero también lo define como un ironista:

En este axioma encuentra también en cierto respecto su justificación el principio de la ironía moderna, sólo que, por una parte, la ironía a menudo está desprovista de toda verdadera seriedad y le encanta deleitarse primordialmente en los temas deleznables, y, por otra, acaba en la mera languidez del ánimo, en vez de en el obrar y el ser efectivamente reales; tal, p. ej., como Novalis, uno de los más nobles ánimos que se situaron en esta perspectiva, fue empujado a la vacuidad de determinados intereses, a esta aversión por la realidad efectiva, y fue presa de esta consunción, por así decir, del espíritu. ${ }^{37}$

Novalis sostiene que la objetividad del mundo exterior es reducible a la subjetividad de la conciencia que lo contempla. De esta manera, el poeta alemán reduce el límite objetivo a la mera conciencia de una limitación concebida por la subjetividad de quien la percibe. La conciencia se presenta así como una tendencia hacia lo infinito, que sólo puede ser obstaculizada por ella misma. El artista es una criatura solitaria, que desdeña el contacto con otros de su especie o la rutina de la vida cotidiana, ya que todos estos casos representan un condicionamiento a su existencia. La ausencia de determinaciones impide al poeta la realización de su interioridad en una obra de arte particular. Pues toda particularidad implica una limitación en contradicción con la infinitud a la que se tiende. Lo infinito se transforma así en un ideal irrealizable en la realidad efectiva, mientras que la conciencia individual se consume en su esterilidad.

\section{Conclusión}

Hemos observado que la concepción hegeliana de "alma bella" guarda ciertas similitudes con la noción de ironía romántica formulada por el mismo autor. La conciencia actuante y el ironista actúan guiándose por sus propias convicciones. Pero la aparente semejanza entre ambos tipos humanos oculta una diferencia sumamente importante. La conciencia que actúa

${ }^{37}$ Op. cit., pp. 119-20. 
sostiene que se rige según su interpretación del deber. Cuando observa que su particular concepción de la universalidad de la ley moral no concuerda con la perspectiva de los demás, se pregunta por el verdadero significado del deber. Su objetivo siempre ha sido la coherencia entre la singularidad de su existencia, las particularidades de la coyuntura en la actúa, y la universalidad del deber. La multiplicidad de posturas con respecto a la naturaleza de la ley moral la obligan a asumir que ha actuado en concordancia con una exégesis personal del deber. Es decir, ha sostenido la coherencia con respecto a una determinación particular, y no con respecto al universal.

El ironista, en cambio, niega la realidad ética exterior: la conciencia irónica reduce la universalidad de la ley moral a una determinación particular puesta por ella. El movimiento de reducción del universal a objeto de la conciencia implica que la subjetividad del ironista es puesta como el fundamento absoluto de la realidad. Hemos comprobado que el resultado de esta operación es la escisión entre el ser-para-sí como lo incondicionado y el ser-en-sí como lo finito y contingente. Semejante contradicción, similar a la observada en la figura de la conciencia denominada "escepticismo", se resuelve con el aislamiento del ironista. La conciencia irónica renuncia a la acción, ya que considera que su actividad es una determinación contingente e irrelevante. El ironista se concentra en la crítica y desestimación de las posturas éticas sostenidas por los demás. Funda su negativa en la consideración de los factores patológicos que alientan el acatamiento de la ley moral. Esta operación de desestimación implica la emergencia de la conciencia irónica como conciencia que juzga el comportamiento de los otros. Es decir, se transforma en el alma bella, inactiva, que somete a juicio a los demás miembros de la sociedad.

En suma, el derrotero de la conciencia irónica nos conduce justamente a la posición del "alma bella". El posterior desarrollo del "alma bella" deriva en la escisión entre la conciencia que juzga y la conciencia que actúa. La evolución de la conciencia actuante nos conduce a la confesión ante la conciencia juzgante y la eventual reconciliación entre ambas. Este último paso es la disolución del "alma bella". La conciencia que actúa no es el origen de la bella subjetividad, sino su fin.

\section{Bibliografía}

Behler, Ernst, "Hegel und Friedrich Schlegel". En Studien zur Romantik und zur idealistischen Philosophie. Paderborn, Ferdinand Schöningh, 1988, pp. 9-45. 
Benjamin, Walter, El concepto de crítica de arte en el romanticismo alemán. Barcelona, Ediciones Península S.A., 1998.

Collins, Richard, "The Comic Dissolution of Art: The Last Act of Hegel's 'Aesthetics'”. En Theatre Journal, 33:1 (1981:Mar.) pp.60-8.

Dupuy, Rosario Casas, "Apuntes sobre la crítica hegeliana de la ironía". En Ideas y Valores, No 110, Agosto 1999, Bogotá, Colombia, pp. 21-31. Hackenesch, Christa, Die Logik der Andersheit. Frankfurt am Main, Athenäum Verlag GmbH, 1987.

Harris, H.S., Hegel's Ladder II: The Odyssey of Spirit. Estados Unidos de América, Hackett Publishing Company, Inc. 1997.

Hegel, Georg Wilhelm Friedrich, Fenomenología del Espíritu. Traducción de Wenceslao Roces con la colaboración de Ricardo Guerra. México DF, Fondo de Cultura Económica, 1966

Hegel, Georg Wilhelm Friedrich, Lecciones sobre la estética, Traducción de Alfredo Brotóns Muñoz. Madrid, Ediciones Akal, S.A., 1989.

Hegel, Georg Wilhelm Friedrich, Rasgos fundamentales de la Filosofía del Derecho o compendio de derecho natural y ciencia del Estado. Traducción de Eduardo Vázquez. Madrid, Editorial Biblioteca Nueva, 2000

Hegel, Georg Wilhelm Friedrich, Vorlesungen über die Geschichte der Philosophie. Tercer tomo. Decimoquinto tomo de Georg Wilhelm Friedrich Hegel's Werke: Vollständige Ausgabe durch einen Verein von Freuden des Verewigten. Berlín, editado por Duncker y Humblot, 1836.

Hegel, Georg, Wilhelm Friedrich, "Solgers nachgelassene Schriften und Briefwechsel”. Segundo artículo. En G.W.F. Hegel: Berliner Schriften 1818-1831, Werke 11. Frankfurt am Main, Suhrkamp Verlag, 1970., pp. 205-74.

Henrich, Dieter, Between Kant and Hegel: Lectures on German Idealism. Estados Unidos, Harvard University Press, 2003

Hirsch, Emanuel, "Die Beisetzung der Romantiker in Hegels Phänomenologie". En Materialen zu Hegels "Phänomenologie des Geistes". Frankfurt am Main, Suhrkamp Verlag, 1973, pp. 245-75.

Kierkegaard, Soren, Sobre el concepto de ironía. Volumen 1 de Soren Kierkegaard: Escritos. Madrid, Editorial Trotta, 2000.

Knowles, Dudley, Hegel and the Philosophy of Right. Londres, Routledge, 2002

Law, Stephen C., "Hegel and the Spirit of Comedy: Der Geist der stets verneint". En AAVV, Hegel and Aesthetics, pp. 113-30.

Lukács, Gyorgy, Ein geschichtsphilosophischer Versuch über die Formen der großen Epik. Berlín, editado por Paul Cassirer, 1920. 
Norman, Judith, "Squaring the Romantic Circle: Hegel's Critique of Schlegel's Theories of Art". En AAVV, Hegel and Aesthetics. Albany, State University of New York, 2000, pp. 131-44.

Paha, Bernhard, Die schöne Seele Hegels und die Literatur der Frühromantik: Studienarbeit. Alemania, GRIN Verlag, 1992.

Pinkard, Terry, capítulo 7: "What is a 'shape of the spirit'?" En AAVV, Hegel's Phenomenology of Spirit. A critical guide. Cambridge University Press, New York, 2008, pp. 112-129.

Pöggeler, Otto, Hegels Kritik der Romantik. Bonn, H. Bouvier u. Co. Verlag, 1956.

Rorty, Richard, Contingency, irony and solidarity. Estados Unidos de América, Cambridge University Press, 1989. https://doi.org/10.1017/ CBO9780511804397

Schlegel, Friedrich, Lucinde. Stuttgart, Christ. Hausmannschen Antiquariats-Buchhandlung, 1835.

Speight, Allen, Hegel, literature and the problem of agency. Cambridge, Cambridge University Press, 2004.

Taylor, Charles, Hegel and modern society. Cambridge, Cambridge University Press, 2003.

Taylor, Charles, Hegel. New York, Cambridge University Press, 1975. https://doi.org/10.1017/CBO9781139171465

Williams, Robert R., "Hegel on Socrates and Irony". En AAVV, Hegel's History of Philosophy: New Interpretations. Albany, State University of New York Press, 2003, pp. 67-86. 